\title{
Use of the Explicit Health Guarantee of Oral Health Care for Pregnant Women at a Family Health Center, Concepción, Chile, 2014-2015
}

\section{Zastosowanie Programu Gwarancji dla Zdrowia Jamy Ustnej w Opiece nad Kobietą w Ciąży w Rodzinnym Centrum Zdrowia w Concepción, Chile, w latach 2014-2015}

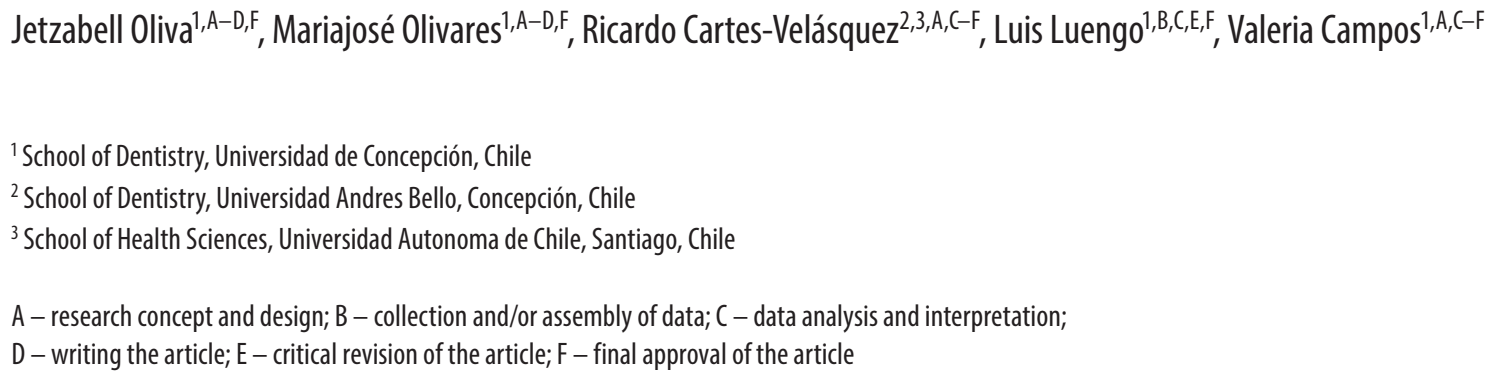

Address for correspondence

Valeria Campos

E-mail: valeriacamposcannobbio@gmail.com

Funding sources

None declared

Conflict of interest

None declared

Received on January 25,2018

Reviewed on January 26,2018

Accepted on February 27, 2018

D0I

$10.17219 / \mathrm{dmp} / 85878$

Copyright

() 2018 by Wroclaw Medical University

and Polish Dental Society

This is an article distributed under the terms of the

Creative Commons Attribution Non-Commercial License

(http://creativecommons.org/licenses/by-nc-nd/4.0/)

\begin{abstract}
Background. Oral health plays a crucial role in general health, quality of life and well-being of pregnant women and their newborns. In Chile, pregnant women have dental care guaranteed by law. However, due to the lack of previous epidemiological studies on the benefits of this guarantee, it is necessary to describe this situation and evaluate the need to change the methods of providing dental services.

Objectives. The objective of this study was to describe the pattern of providing dental benefits resulting from the Explicit Health Guarantee - Integral Oral Health in PregnantWomen (GES-SOIE) program to pregnant women attending the Juan Soto Fernández Family Health Center, Concepción, Chile, in 2014-2015.

Material and methods. A cross-sectional study of the electronic dental records of patients admitted to GES-SOIE was conducted. The variables studied were sociodemographic data, dental chair hours, non-attendance, treatment completion, and the type of referral to secondary healthcare (SHC).

Results. Of 233 pregnant women, $65.2 \%$ were registered for non-attendance, $21.2 \%$ required referral to SHC and $76.4 \%$ completed their treatment. When performing logistic regression, it was found that for each non-attendance the chance of not completing the treatment increased 1.4 times.

Conclusions. The level of non-attendance and opting out of the treatment in pregnant women is high, which hinders the proper functioning and effectiveness of GES-SOIE.
\end{abstract}

Key words: pregnant women, dental care, dental health services

Słowa kluczowe: kobiety w ciąży, opieka dentystyczna, świadczenia dentystyczne 
Oral health plays a crucial role in general health, quality of life and well-being of pregnant women and their newborns. ${ }^{1-2}$ It is known that the oral cavity is affected by the multiple changes that occur during pregnancy, increasing the predisposition to periodontal diseases, induced by bacterial plaque and exacerbated by the release of steroid hormones. ${ }^{3-7}$ In addition, a decrease in salivary $\mathrm{pH}$ and the buffer effect, together with diet changes, lead to an increase of cariogenic risk. ${ }^{8-10}$

The association between periodontal disease and premature birth, low birth weight and preeclampsia has been established. On the other hand, active caries in pregnant women is a risk factor for the development of early childhood caries in their future children. Thus, proper oral healthcare of pregnant women is essential, with the intention of reducing both these adverse effects during pregnancy and the transmission of cariogenic bacteria to the infant. ${ }^{1}$ This is why the state of pregnant women's oral health is considered a public health problem.

Given the above, in Chile in 2010, the Integral Oral Health in Pregnant Women program (GES-SOIE) was introduced within the Explicit Health Guarantees (GES). ${ }^{11}$ GES is a Chilean health public policy that constitutes a set of benefits guaranteed by law for people affiliated with the National Health Fund (FONASA), a public body with state funding, and the Health Insurance Institutions (ISAPRE), which from a private health insurance system. Users receive appropriate treatments, with financial support, for health problems that fall within the GES scope, with certified quality and in terms guaranteed by law. ${ }^{12}$ Specifically, GESSOIE provides dental care aimed at educating, preventing, recovering, and rehabilitating oral health, thus contributing to the formation of a healthy environment that promotes and protects oral health. ${ }^{11}$

For FONASA affiliates, GES-SOIE is comprised of free primary oral healthcare, including preventive and restorative treatment, performed by general dentists at Public Family Health Centers (CESFAMs), and secondary oral healthcare, which includes specialty treatment and is generally performed in referral centers by specialty dentists. ${ }^{11,12}$ Unfortunately, according to the findings of Núnez et al., only $31 \%$ of pregnant women were receiving dental care, which shows the underutilization of GES. ${ }^{13}$

Due to the lack of previous epidemiological studies on the delivery of the benefits of GES, it is necessary to describe this situation and evaluate the need to change the approach in providing dental services. Therefore, the objective of this study was to describe the pattern of providing of the dental benefits of GES-SOIE to pregnant women attending the Juan Soto Fernández CESFAM, Concepción, Chile, in 2014-2015.

\section{Material and methods}

A cross-sectional study was carried out based on the dental electronic records of pregnant women admitted to GES-SOIE. Approval was obtained from the Commission of Research and Bioethics of the Faculty of Dentistry of the University of Concepción, Chile, and the Scientific Ethics Committee of the Concepción Health Service.

The population of interest was composed with the use of dental electronic records of the entire group of pregnant women, belonging to Juan Soto Fernández CESFAM, between 2014 and 2015 (237 records). Four incomplete electronic records, and those of patients who at the time of data collection were still during treatment, were excluded. The variables studied were sociodemographic data, number of dental appointments undergone, nonattendance, treatment completion, referral to secondary healthcare (SHC), and the type of referral. Data collection was performed by 2 researchers between May and June 2016, and the data was registered in Microsoft Excel v. 2013 (Microsoft, Redmond, USA).

A univariate analysis was carried out, using frequency tables, summary measures (central tendency and dispersion) and relevant graphs. Then, a bivariate analysis was performed with summary measures, contingency tables and grouped bar charts. Finally, to study the relationship between qualitative variables, Spearman's correlation test was applied. Furthermore, logistic regression and an analysis of maximum sensitivity and specificity were carried out. The analysis of the data was performed with the InfoStat v. 2014 software (InfoStat, Córdoba, Argentine). This is a census study, thus no statistical significance was calculated.

\section{Results}

From a total of 233 records analyzed, the largest amount of admissions was in 2015 (59\%), with an average patient age of 26.5 years. From the total number of pregnant women, $65.2 \%$ had at least 1 non-attendance with a maximum of 12 non-attendances registered. Of the patients referred to $\mathrm{SHC}, 78.8 \%$ required only 1 specialty treatment. Within the referrals, the specialties of endodontics and surgery comprised $85.7 \%$ of total referrals (Table 1 ).

Between 2014 and 2015, 1,293 dental appointments were requested, of which $34.8 \%$ resulted in non-attendances. From a total of 843 appointments executed in pregnant women covered by the GES-SOIE plan, $74.9 \%$ were in the case of patients who completed their dental treatment (Table 2).

Pregnant women referred to SHC required an average of 5.7 appointments to complete their dental treatment, and those not referred to SHC required an average of 3.1 appointments. No correlation was found between the age of the patients, and the number of appointments executed and the number of absences (Spearman's correlation coefficient -0.09 and -0.12 , respectively). 
Table 1. Characterization of pregnant women admitted to GES-SOIE, 2014-2015

\begin{tabular}{|c|c|c|c|c|c|}
\hline \multicolumn{2}{|c|}{ Pregnant women } & $15-24$ years old $(\%)$ & $25-34$ years old $(\%)$ & $35-44$ years old $(\%)$ & Total (\%) \\
\hline \multirow{2}{*}{ Year of admission } & 2014 & $45(46.4)$ & $39(40.2)$ & $13(13.4)$ & $97(100)$ \\
\hline & 2015 & $60(44.1)$ & $53(39.0)$ & $23(16.9)$ & $136(100)$ \\
\hline \multicolumn{2}{|l|}{ At least 1 non-attendance } & $77(73.3)$ & $56(60.9)$ & $19(52.8)$ & $152(65.2)$ \\
\hline \multicolumn{2}{|l|}{ Dental treatment completion } & $79(75.2)$ & $72(78.3)$ & $27(75.0)$ & $178(76.4)$ \\
\hline \multicolumn{2}{|l|}{ SHC referral } & $22(21.4)$ & $17(18.5)$ & $10(27.8)$ & $49(21.2)$ \\
\hline \multirow{4}{*}{ Type of referral } & endodontics & $16(15.2)$ & $11(12)$ & $8(22.2)$ & $35(15.0)$ \\
\hline & surgery & $8(7.6)$ & $4(4.3)$ & $1(4,3)$ & $13(5.6)$ \\
\hline & removable prosthesis & $0(0)$ & $3(3.3)$ & $4(11.1)$ & $7(3.0)$ \\
\hline & periodontics & $0(0)$ & $0(0)$ & $1(2.8)$ & $1(0.4)$ \\
\hline \multirow{3}{*}{$\begin{array}{l}\text { Dental appointments requested } \\
\text { per pregnant woman* }\end{array}$} & $1-5$ appointments & $58(55.8)$ & $51(55.4)$ & $24(66.7)$ & $133(57.3)$ \\
\hline & 6-10 appointments & $31(29.8)$ & $30(32.6)$ & $8(22.2)$ & $69(29.7)$ \\
\hline & $>10$ appointments & $15(14.4)$ & $11(12.0)$ & $4(11.1)$ & $30(12.9)$ \\
\hline
\end{tabular}

GES-SOIE - Explicit Health Guarantee - Integral Oral Health in Pregnant Women; SHC - secondary healthcare; * attendance + non-attendance.

Table 2. Distribution of appointments requested by pregnant women admitted to GES-SOIE, 2014-2015

\begin{tabular}{|c|c|c|c|c|}
\hline \multirow{2}{*}{ Appointments } & \multicolumn{3}{|c|}{ Age range } & \multirow{2}{*}{ Total } \\
\hline & $15-24$ & $25-34$ & $35-44$ & \\
\hline $\begin{array}{l}\text { Appointments undergone* } \\
\text { (average number of appointments per pregnant woman) }\end{array}$ & $\begin{array}{r}396 \\
(3.8)\end{array}$ & $\begin{array}{r}327 \\
(3.6)\end{array}$ & $\begin{array}{r}120 \\
(3.3)\end{array}$ & $\begin{array}{r}843 \\
(3.6)\end{array}$ \\
\hline $\begin{array}{l}\text { Appointments undergone per dental treatment completion** } \\
\text { (average number of appointments per pregnant woman) }\end{array}$ & $\begin{array}{r}308 \\
(3.9)\end{array}$ & $\begin{array}{r}249 \\
(3.5)\end{array}$ & $\begin{array}{r}83 \\
(3.1)\end{array}$ & $\begin{array}{r}640 \\
(3.6)\end{array}$ \\
\hline $\begin{array}{l}\text { Number of non-attendances*** } \\
\text { (average number of appointments per pregnant woman) }\end{array}$ & $\begin{array}{r}216 \\
(2.8)\end{array}$ & $\begin{array}{r}185 \\
(3.3)\end{array}$ & $\begin{array}{r}49 \\
(2.6)\end{array}$ & $\begin{array}{r}450 \\
(3.0)\end{array}$ \\
\hline
\end{tabular}

GES-SOIE - Explicit Health Guarantee - Integral Oral Health in Pregnant Women; * total number of appointments undergone with and without dental treatment completion; ${ }^{* *}$ total number of appointments undergone per pregnant woman that completed her dental treatment; ${ }^{* * *}$ total number of non-attendances with and without dental treatment completion.

When performing logistic regression with the event "completing the dental treatment" and the number of non-attendances as a predictor, it was found that for each absence, the chance of not completing the dental treatment increased 1.4 times. This did not change when controls for the age variable were applied. When carrying out an analysis of maximum sensitivity and specificity for the outcome of the event "not completing the dental treatment", we found a cut-off value close to 3 absences (receiver operating characteristic $(\mathrm{ROC})$ curve area $=0.663 \pm 0.047$; $\mathrm{p}=0.0003)$ (Fig. 1).

\section{Discussion}

Regarding the data obtained in this study, approx. a quarter of pregnant women admitted to GES-SOIE did not complete their treatment. In addition, more than half of this population had repeated absences. This situation unnecessarily extends treatment time, since, according to the results obtained, around the $4^{\text {th }}$ appointment, the pregnant patient should have had her treatment completed, with only a small percentage of patients requiring referral to a specialist.
A similar scenario was reported by Núñez et al., who showed that $69 \%$ of Chilean pregnant women did not receive dental care, which is in contrast to the observations by Fuentes-Fernández, who reported that $98 \%$ of pregnant women believed that it was necessary to consult the dentist during pregnancy. ${ }^{13,14}$ This is a worrisome situation because, according to national data, the oral health status of Chilean pregnant women is poor, with $38.1 \%$ of women between 17 and 24 years of age being partially edentulous, increasing to $65.5 \%$ in the case of women $25-44$ years old. ${ }^{11}$

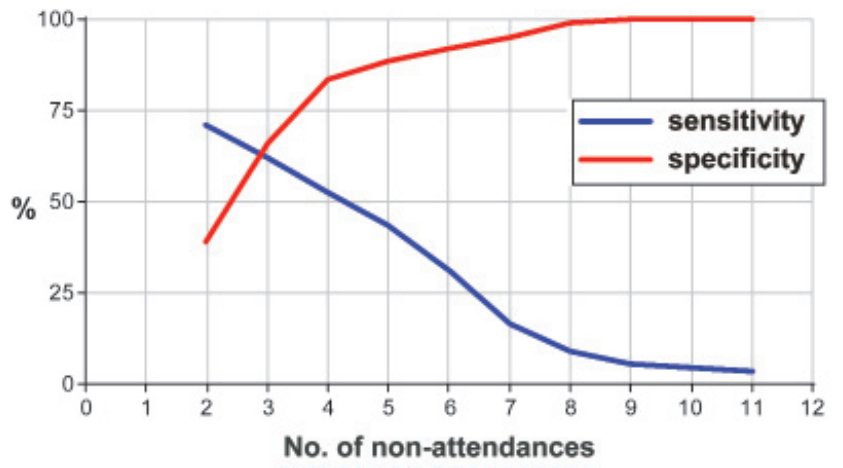

Fig. 1. Maximum analysis of sensitivity and specificity for dental treatment completion 
Regarding the referrals, unlike in the report by Norambuena-Suazo and Palma-Cárdenas where 7 pregnant women required referral to periodontal treatment, in our study only 1 pregnant woman required such referral. $^{7}$ This difference may be due to our study design, using a secondary data source, in addition to the non-registration of a periodontal examination, in contrast with the Norambuena-Suazo and Palma-Cárdenas's study, where a primary data source was used and the data was, collected by calibrated examiners using the Community Periodontal Index of Treatment Needs (CPTIN). ${ }^{7}$

Every time a pregnant woman misses her dental appointment, the risk of not completing the dental treatment increases, which is why it is recommended that local interventions be carried out (rescue, phone calls, motivating, etc.) regarding the patients who already have 2 nonattendances.

It should be pointed out that each dental appointment on the premises of CESFAM lasts $20 \mathrm{~min}$; therefore, the 1,293 sessions delivered to pregnant patients correspond to 48 working days, that is, 2 months and 1 week. When calculating the number of absences into working days, they correspond to 23 8-hour workdays, time during which 1 of the 2 dental offices of CESFAM is not providing dental care to the rest of the community, because the appointment vacancies are filled by these patients who do not show up for their dental appointment.

The delivery pattern of GES-SOIE involves multiple variables. In this study, using a database made it possible to perform calculations and estimates regarding the use of GES, but it did not allow us to identify the reasons for non-attendance and treatment dropouts.

Since a similar scenario is present internationally, where most pregnant women do not request dental care, many studies have tried to identify the possible causes of this behavior. ${ }^{15-19}$ As reported in Malaysia and Mexico, the main reasons why pregnant women do not request dental care are long waiting times in the clinics, lack of immediate dental care and economic factors. ${ }^{15,16}$ However, although these problems would be resolved by GES, there is an underutilization of GES. It should be remembered that primary healthcare (PHC) in Chile is free and, as this is a health problem covered by GES, it categorizes pregnant women as a priority when requesting dental care, because they are included in the healthcare goals that must be met year after year in every CESFAM. ${ }^{11}$

Other possible causes of this underutilization could be the ignorance of the harmlessness of dental treatment during pregnancy, low oral health literacy, ignorance of the effect of oral health in pregnancy, and dental anxiety. ${ }^{16-19}$ However, as Cantarutti et al. mention, international literature does not necessarily apply to Chilean reality, due to cultural differences and the characteristics of its health system..$^{20}$ We suggest performing prospective national studies with a larger sample size, in different health centers and with the incorporation of other variables, consid- ering both quantitative and qualitative approaches, in order to recognize the barriers that are responsible for this pattern. Such information would be useful for an early identification of pregnant women at risk of absenteeism and GES-SOIE dropouts, as well as for designing strategies aimed at removing these barriers and improving care. This would allow for the improvement of oral health in pregnant woman, optimizing the limited resources of the public service.

Among the limitations of this study is the use of a secondary database, in which 4 incomplete records were noticed, and that the database could present other unperceived typing errors. In addition, the variability existing among professionals while completing of the electronic clinical records and the lack of standardization of the registry must be considered, as they made it impossible to analyze more variables, such as the Chronic Obstructive Pulmonary Disease (COPD) index and number of pregnancies, among others. Another limitation of this study is the representativeness of the population, with a restricted sample size, which represented only pregnant women who requested GES, and that the data was limited to a single CESFAM.

Dental care covered by GES-SOIE consists mainly of PHC services, with few referrals to SHC, so it could be inferred that it is possible to provide the majority of dental treatments in CESFAMs; however, the level of nonattendance and treatment dropouts is high, which hinders the proper functioning and effectiveness of GES.

In Chile, pregnant women have comprehensive dental care guaranteed by law. However, there are no records of the pattern of delivery of these dental benefits, regarding the number of absences and dropouts of the treatment. In the present study it was possible to quantify that $65.2 \%$ of the studied pregnant women presented absences and $23.6 \%$ did not complete their dental treatment. Identifying this underutilization highlights the need to design strategies aimed at optimizing the limited resources of the public service. It is also necessary to identify the causes of this underutilization and, from there, implement strategies to improve adherence to dental treatment.

\section{References}

1. American Academy on Pediatric Dentistry Council on Clinical Affairs. Guideline on perinatal oral health care. Pediatr Dent. 2011;32:109-113.

2. Shahnazi H, Hosseintalaei M, Ghashghaei FE, Charkazi A, Yahyavi Y, Sharifirad G. Effect of educational intervention on perceived susceptibility self-efficacy and DMFT of pregnant women. Iran Red Crescent Med J. 2016;18:e24960. doi: 10.5812/ircmj.24960

3. Zhong C, Ma KN, Wong YS, So Y, Lee PC, Yang Y. Oral health knowledge of pregnant women on pregnancy gingivitis and children's oral health. J Clin Pediatr Dent. 2015;39:105-108.

4. Gümüs P, Öztürk VÖ, Bozkurt E, Emingil G. Evaluation of the gingival inflammation in pregnancy and postpartum via 25-hydroxyvitamin D3, prostaglandin E2 and TNF-a levels in saliva. Arch Oral Biol. 2016;63:1-6.

5. Usin MM, Tabares SM, Parodi RJ, Sembaj A. Periodontal conditions during the pregnancy associated with periodontal pathogens. J Investig Clin Dent. 2013;4:54-59. 
6. Wu M, Chen SW, Jiang SY. Relationship between gingival inflammation and pregnancy. Mediators Inflamm. 2015:623427.

7. Norambuena-Suazo P, Palma-Cárdenas I. Periodontal treatment needs in pregnant women, Frutillar, Chile, 2015 [in Spanish]. Rev Clínica Periodoncia, Implantol. y Rehabil Oral. 2016;9:121-124.

8. Kamate WI, Vibhute NA, Baad RK. Estimation of DMFT, salivary Streptococcus mutans count, flow rate, $\mathrm{pH}$, and salivary total calcium content in pregnant and non-pregnant women: A prospective study. J Clin Diagn Res. 2017;11:ZC147-ZC151.

9. Saluja P, Shetty V, Dave A, Arora M, Hans V, Madan A. Comparative evaluation of the effect of menstruation, pregnancy and menopause on salivary flow rate, $\mathrm{pH}$ and gustatory function. $J$ Clin Diagn Res. 2014;8:ZC81-ZC85.

10. Vergnes JN, Kaminski M, Lelong N, Musset AM, Sixou M, Nabet C. Frequency and risk indicators of tooth decay among pregnant women in France: A cross-sectional analysis. PLoS One. 2012;7:e33296. https://doi.org/10.1371/journal.pone.0033296

11. Ministry of Health of Chile. Guía Clínica Salud Oral Integral de la Embarazada. Santiago, Chile: Ministerio de Salud (MINSAL); 2013.

12. Laurell AC, Ronquillo JH. The Second Health Reform. Insurance and payer-provider split [in Spanish]. Salud Col 2010;6:137-148.

13. Núñez J, Moya P, Monsalves MJ, Landaeta S. Oral health leve of knowledge and use of dental GES in puerperal patients at a private clinic, Santiago, Chile. IInt J Odontostomatol. 2013;7:39-46.

14. Fuentes Fernández R, Oporto Venegas G, Alarcón AM, Bustos Medina L, Prieto Gómez R, Rico Williams H. Opinion and beliefs of pregnancy women in prenatal control related to oral health and pregnant [in Spanish]. Av Odontoestomatol. 2009;25:147-154.

15. Saddki N, Yusoff A, Hwang YL. Factors associated with dental visit and barriers to utilization of oral health care services in a sample of antenatal mothers in Hospital Universiti Sains Malaysia. BMC Public Health. 2010;10:75. doi: 10.1186/1471-2458-10-75

16. Cruz G, Núñez G, Salinas A, Ramos E, Sánchez R. Factors associated with the use of dental health services in primary care in northeastern Mexico. J Oral Res. 2016;5:240-247.

17. Dinas K, Achyropoulos V, Hatzipantelis E, et al. Pregnancy and oral health: Utilization of dental services during pregnancy in northern Greece. Acta Obstet Gynecol Scand. 2007;86:938-944.

18. Martínez-Delgado CM. Some considerations on the Latin American oral health literacy. J Oral Res. 2016;5:59-60.

19. Le M, Riedy C, Weinstein P, Milgrom P. Barriers to utilization of dental services during pregnancy: A qualitative analysis. J Dent Child (Chic). 2009;76:46-52.

20. Cantarutti C, Veliz C, Madariaga $P$, et al. What are the barriers to access to dental care for pregnant women? A review of the literature [in Spanish]. Ars Medica Rev Ciencias Méd. 2017;42:50-54. 
